\title{
Cost of maternal health services in selected primary care centres in Ghana: a step down allocation approach
}

Maxwell Ayindenaba Dalaba ${ }^{1,2^{*}}$, Patricia Akweongo ${ }^{3}$, Germain Savadogo ${ }^{1}$, Happiness Saronga ${ }^{1,4}$, John Williams ${ }^{2}$, Rainer Sauerborn ${ }^{1}$, Hengjin Dong ${ }^{1,5}$ and Svetla Loukanova ${ }^{1}$

\begin{abstract}
Background: There is a paucity of knowledge on the cost of health care services in Ghana. This poses a challenge in the economic evaluation of programmes and inhibits policy makers in making decisions about allocation of resources to improve health care. This study analysed the overall cost of providing health services in selected primary health centres and how much of the cost is attributed to the provision of antenatal and delivery services.

Methods: The study has a cross-sectional design and quantitative data was collected between July and December 2010. Twelve government run primary health centres in the Kassena-Nankana and Builsa districts of Ghana were randomly selected for the study. All health-care related costs for the year 2010 were collected from a public service provider's perspective. The step-down allocation approach recommended by World Health Organization was used for the analysis.

Results: The average annual cost of operating a health centre was $\$ 136,014$ US. The mean costs attributable to ANC and delivery services were $\$ 23,063$ US and $\$ 11,543$ US respectively. Personnel accounted for the largest proportion of cost (45\%). Overall, ANC (17\%) and delivery (8\%) were responsible for less than a quarter of the total cost of operating the health centres. By disaggregating the costs, the average recurrent cost was estimated at $\$ 127,475$ US, representing $93.7 \%$ of the total cost. Even though maternal health services are free, utilization of these services at the health centres were low, particularly for delivery (49\%), leading to high unit costs. The mean unit costs were \$18 US for an ANC visit and \$63 US for spontaneous delivery.

Conclusion: The high unit costs reflect underutilization of the existing capacities of health centres and indicate the need to encourage patients to use health centres. The study provides useful information that could be used for cost effectiveness analyses of maternal and neonatal care interventions, as well as for policy makers to make appropriate decisions regarding the allocation and sustainability of health care resources.
\end{abstract}

Keywords: Cost, Step-down allocation approach, Antenatal care, Delivery, Maternal health service, Ghana

\section{Background}

Reducing maternal and under-five mortality through the use of cost-effective strategies continues to be a challenge, particularly in developing countries. The worldwide maternal mortality ratio (MMR), or the number of women who die during pregnancy and childbirth per 100,000 live births, declined from 299 in 1990 to 202 in 2011, representing a $1.9 \%$ average annual rate of decline. Globally, under-five

\footnotetext{
* Correspondence: madalaba@yahoo.com

${ }^{1}$ Institute of Public Health, University of Heidelberg, Heidelberg, Germany

${ }^{2}$ Navrongo Health Research Centre, Navrongo, Ghana

Full list of author information is available at the end of the article
}

mortality also declined over the past years reaching 7.2 million in 2011 [1].

In Ghana, the MMR declined from 394 deaths per 100,000 live births in 1990 to 328 deaths per 100,000 live births in 2011, a $0.9 \%$ average annual rate of decline. Also under 5 deaths in the country was estimated at 47,600 deaths in 2011 [1]. In the Kassena-Nankana and the Builsa districts, however, the MMR was high at 367 and 259 maternal deaths per 100,000 live births in 2010 respectively $[2,3]$.

Given the limited health care resources in Ghana, coupled with the wide range of maternal and neonatal

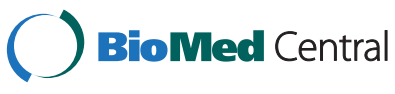


care (MNC) services provided free of charge for all women, efficient use of these resources is essential. Despite the need to maximize resources, few cost studies have been conducted in Ghana, and as a result there is little information on the costs of antenatal care (ANC) and delivery services.

This study aims to fill this crucial gap by examining the costs associated with running a health care centre as well as the specific costs associated with ANC and delivery services. This knowledge can better enable health centre managers and policy makers to budget and allocate the appropriate resources that will ensure higher quality of health care services towards reducing maternal and under-five mortality.

\section{Methods}

\section{Study area}

This study was carried out in the Kassena-Nankana and Builsa Districts located in the northern part of Ghana. The Kassena-Nankana District (KND) occupies an area of about 1,675 square kilometres with a population of approximately 150,000 [4]. The district has a hospital, seven health centres, one private clinic and twenty seven Community-based Health Planning and Services (CHPS) compounds with resident Community Health Officers (CHOs) offering doorstep services [5].

The Builsa district lies southwest of the KND and covers an area of 2,220 square kilometres with a population of approximately 95,800 . It is served by a district hospital, eight health centres and thirteen CHPS compounds [2].

\section{Study design}

The study has a cross-sectional design and quantitative data was collected from the health provider perspective. Patient costs were not collected and hence not included in the analysis. The study is part of the Quality of Maternal and Prenatal Care (QUALMAT) project, which aims to improve the quality of maternal and prenatal care in Ghana by testing two interventions-a computer-assisted clinical decision support system and performance-based incentives. Details of the QUALMAT project are presented elsewhere [6].

The districts and health centres included in this study were selected by the QUALMAT project based on the criteria that they were typical for the country, and were comparable according to national norms in terms of medical infrastructure, equipment and staffing.

\section{Selected health care centres}

Twelve government run primary health care centres were included in the study (Table 1). In Ghana, health service delivery is organized in five levels: tertiary, regional, district, sub-district (health centres and clinics), and community level. The health care centres included in this study fall under the sub-district level and all met the minimum requirement of having at least one nurse, one midwife, and one medical assistant. The health centres provide outpatient services and normal deliveries.

Though all the health centres included in this study have the minimum staff, the staff strength at each health centre differs. For instance, whereas the Wiaga Health Centre had a staff strength of 22, that of Doninga Health Centre was only 4 (Table 1 ). In addition, the year of construction of the health centres and the start of operations differed between the health centres. Whereas some of the health centres started operating in the 1950's (Wiaga), others were only opened after 2000 (Doninga, Kologo, Fumbisi and Kassena-Nankana East).

Though all the study health centres had basic infrastructure such as utilities (electricity, water), equipment (sphygmomanometer, thermometer, stethoscope, weighing scales etc.), medical supplies (urine testing kits, cannula, giving sets, syringes and needles, cotton, gauze, etc.), vehicles (motorbikes), drugs (amoxicillin, gentamicin, SP, iron, etc.), the out-of-stock items varied between the health care centres.

The catchment areas of the health centres also varied. Doninga health centre covered the smallest population of about 2,083 residents, and Wiaga covered 20,444 residents (Table 1). Though Wiaga is a health centre, it serves as a referral point and sometimes provides inpatient care. The health centre is believed to provide quality care due to it being a missionary facility, run by the Catholic Church. For this reason, a good proportion of patients visiting the Wiaga health centre are not within its catchment area.

\section{Table 1 Background characteristics of health centres}

\begin{tabular}{llll}
\hline Health care centres & $\begin{array}{l}\text { Year of start } \\
\text { of operation }\end{array}$ & $\begin{array}{l}\text { Population } \\
\text { covered }\end{array}$ & $\begin{array}{l}\text { Number } \\
\text { of staff }\end{array}$ \\
\hline Paga & 1986 & 13,588 & 10 \\
Chiana & 1966 & 14,361 & 18 \\
Kassena-Nankana East (KNE) & 2002 & 15,940 & 10 \\
Sirigu & 1984 & 8,519 & 10 \\
Navrongo Health Centre (NHC) & 2010 & 16,003 & 17 \\
Kolgo & 1999 & 14,361 & 7 \\
Chuchulga & 1998 & 11,370 & 10 \\
Kanjaga & 2000 & 11,365 & 13 \\
Siniensi & 1969 & 7,541 & 19 \\
Doninga & 2003 & 2,083 & 4 \\
Wiaga & 1950 & 20,444 & 22 \\
Fumbisi & 2005 & 15,197 & 21 \\
Total & & $\mathbf{1 5 0 , 7 7 2}$ & $\mathbf{1 6 1}$ \\
Average & & $\mathbf{1 2 , 5 6 4}$ & $\mathbf{1 3}$ \\
Median & & $\mathbf{1 3 , 9 7 5}$ & $\mathbf{1 0}$ \\
\hline
\end{tabular}




\section{Data collection}

Data was collected between July and December 2010. All health care related costs collected in the data covered a one- year period (2010). A standard structured health facility questionnaire was used to collect data and included nine sections: building, equipment, vehicle, human resources/personnel, existing incentives, supplies, operations and maintenance costs (Table 2).

The data were collected through interviews with health centre staff, document review, physical measuring of rooms and counts of equipment. The prices of items were obtained through store -keeper invoices or from the regional medical stores. In order to calculate staff salaries, the average salaries per staff type were graded as indicated by the Ministry of Health [7]. We determined the percentage work time or workload by staff for each department via interviews. Utilization data, such as number of ANC visits and the number of deliveries at the various health centres, were also collected via document reviews.

Data was entered in Epi info version 3.5.1 and analyzed using Microsoft Office Excel 2007. Ethical clearance was obtained from the ethics committee of the University of Heidelberg and the Institutional Review Board of the Navrongo Health Research Centre in Ghana.

\section{Cost estimation}

Annual costs for the year 2010 were calculated for each of the twelve health centres. While there are several methods in costing health care services, a systematic review of costing methods conducted by Mogyorosy et al. (2005) concluded that no method is better than the others in all criteria. Rather, the choice of method depends on available data, the study setting and other factors [8]. Taking these criteria into consideration, we used the step-down allocation (SDA) approach as discussed in the WHO manual [9] and Conteh (2004) and used in other studies [10-12].

\section{Step down allocation approach}

The step-down allocation (SDA) approach is a method in which the resources necessary to run a health centre are first identified and then allotted to selected cost centres or service departments on an allocation basis [13,14]. The costs centres are usually ranked according to importance and the costs are being assigned to centres lower down the scale in a step-wise fashion [8]. Using SDA approach, we followed six main steps: (1) defining the final product, (2) defining cost centres, (3) identifying the full cost for each input, (4) assigning inputs to cost centres, (5) allocating all costs to final cost centres, and (6) computing total and unit costs.

Accordingly, costs for each of the twelve health centres were calculated using full costing approach, which required the calculation of both capital and recurrent costs. We defined the final product as antenatal and delivery services.

Secondly, we defined cost centres/categories based on the functions of the departments. Three cost centres were identified: direct, intermediate and indirect costs centres. Direct costs centres, or final cost centres, refer to the cost of services provided directly to patients $[10,13,15]$. It is the final level of cost centres that Conteh refers to as the 'endpoints of the production line' [13]. In our study, the direct cost centres were the ANC, delivery services and other care (e.g. inpatient, outpatient, family planning, etc.). Intermediate cost centres refer to costs of diagnostic and departmental support to the direct cost centres, which we identified as the pharmacy and laboratory departments.

Table 2 Cost categories

\begin{tabular}{|c|c|}
\hline Category & Description \\
\hline \multicolumn{2}{|l|}{ A. Recurrent cost } \\
\hline Personnel cost & $\begin{array}{l}\text { It includes gross income of staff (including volunteer workers), complements of earnings (i.e. housing allowances, } \\
\text { overtime, car allowances), human resource costs( cost of training for staff for at least } 1 \text { year during the last } 3 \text { years) } \\
\text { and cost of performance -based incentives (both monetary and value of non-monetary). }\end{array}$ \\
\hline Administrative cost & $\begin{array}{l}\text { It includes electricity, water, telephone bills, cleaning products, repairs, post office, printing, photocopying, and stationary. } \\
\text { In addition, cost of spare parts purchased, servicing of the means of transport, fuels and lubricants consumed } \\
\text { were also included. }\end{array}$ \\
\hline Pharmacy costs & These costs included the costs of drugs and vaccines consumed within the period. \\
\hline Laboratory costs & This group included all laboratory supplies used in the period. \\
\hline Medical supplies cost & This group included all medical consumables used in the period. \\
\hline \multicolumn{2}{|l|}{ B. Capital cost } \\
\hline Cost of building & $\begin{array}{l}\text { It refers to all the rooms in the health care centre. The total area for the various rooms measured was } \\
\text { multiplied by the cost per meter square to give the total replacement value. The cost per meter } \\
\text { squared was obtained from the Estate officer at the district assembly ( } \$ 14 \text { US per meter squared). }\end{array}$ \\
\hline Vehicle costs & These included all vehicle costs (motorcycles, four-wheel vehicles, three wheel vehicles, ambulance and bicycles). \\
\hline Equipment cost & $\begin{array}{l}\text { It includes cost of general equipment and equipment in the various rooms (waiting room, consulting room etc.) } \\
\text { such as benches, tables, chairs etc. }\end{array}$ \\
\hline
\end{tabular}


The indirect cost centres or overhead costs refer to costs incurred by departments or activities that provide services only to other departments of the health care centre, not directly to patients. In this category we included administration and vehicle costs for our analysis.

In the third step, we identified the full cost for each input. We generated a list of all resources and grouped them into the following categories (Table 2)-personnel, administration, pharmacy, vaccines, laboratory, medical supplies (representing recurrent or running costs of health centres), building, vehicle and equipment costs (representing capital costs). The total annual costs were estimated by multiplying and summing quantities consumed or available on each specific item by the unit price. In addition, donated items were valued and included in the cost calculation.

Capital costs, resources whose lifespan is greater than one year, were also calculated. There are several methods of measuring and valuing capital costs in economic evaluation, but the best method is to annuitize capital outlay over the useful life asset, which represents the equivalent annual cost [14]. Capital costs were annualized using a discount rate with their respective useful life years. A discount rate of 3\% was chosen in conformity with most economic evaluation studies conducted in developed and developing countries $[9,10,16,17]$ and in the absence of any accepted alternative rate used in Ghana. Based on expert opinion and literature review a useful life of 10 years was used for equipment and 30 years for building [9-11,18].

In the fourth step, we assigned the categorized costs to the three cost centres. Some costs can be assigned immediately to certain cost centres. Accordingly, personnel, administration, pharmacy, laboratory and vehicle costs were assigned directly to the relevant cost centres. Personnel cost was assigned first as it accounted for the largest share of costs. In addition, medical supplies, building cost, equipment were distributed to direct cost centres.

In the fifth step, we reallocated all costs from the two cost centres (indirect and intermediate cost centres) to the direct cost centres (ANC, delivery and others). In the final step, we calculated unit costs. The allocated costs for each direct cost centre were divided by the outputs of each of these centres. Unit cost (average cost) refers to the cost of providing a single good or service [13]. Accordingly, the unit cost for ANC was calculated by dividing the total cost of ANC over the total number of ANC consultations conducted in the year irrespective of the number of women who made multiple visits. The unit cost for delivery was calculated by dividing the total cost of delivery over the total number of deliveries in the year.

\section{Other calculations}

We estimated the number of ANC visits based on the recommended minimum of four visits for focused ANC by dividing the total number of ANC visits by 4 . All costs in this study were collected in local currency, Ghana cedis (GH\$), and were converted to US\$ during data analysis using the average exchange rate for 2010 (1US\$= GH\$1.5).

\section{Sensitivity analysis}

One-way sensitivity analysis was conducted to explore the impact of changes of variables that are susceptible to change over time or in different settings so as to assist in the generalization of the study results. This was done by changing each variable through the range of interest or assumptions, while holding other variables constant. Thus, all variables remained constant except the variable of interest.

Given that several studies use 3-5\% discount rates, sensitivity analysis was done to assess the impact of using a higher discount rate (5\%). The life span of buildings was also varied (from 30 years to 20 years). In addition, given that countries are embarking on several interventions and reforms to encourage women to attend ANC and deliver at the health centre, we expect a future increase in utilization of ANC and delivery services at the health centres. A sensitivity analysis was therefore performed assuming a 10\% increase in ANC visits and delivery. Thereafter the threshold for significance was set at $10 \%$ change in costs or higher.

\section{Results}

\section{Cost distribution}

The average cost (capital and recurrent costs) of operating the 12 primary health centres (Table 3 ) in a year was estimated as $\$ 136,014$ US (median $=\$ 132,178$ US), with a range from $\$ 27,727$ US to $\$ 389,985$ US. The Wiaga Health Centre had the highest overall health care cost $(\$ 389,985$ US) with the highest average costs for ANC $(\$ 86,286$ US) and delivery ( $\$ 38,002$ US) as well. This is not surprising as the health centre is large with more staff, more resources and a larger catchment area compared with the other health centres (Table 1).

Of the overall total health centre cost, the highest proportion was spent on personnel (45\%), followed by pharmacy (39\%). Administration (7.3\%) and building related costs $(0.14 \%)$ contributed less than $10 \%$ to total health centre costs. By disaggregating the costs, the average recurrent cost (administration, pharmacy, laboratory and medical supplies costs) was estimated as $\$ 127,475$ US (median= $\$ 122,941 \mathrm{US}$ ), representing $93.7 \%$ of total costs.

\section{Cost of antenatal care and delivery}

The estimated cost attributed to ANC and delivery differed substantially between health centres. The cost attributable to ANC services for all the health centres ranged from $\$ 2,707$ US to $\$ 86,286$ US, with an average 
Table 3 Cost distribution by health care centre (US\$)

\begin{tabular}{|c|c|c|c|c|c|c|c|c|c|}
\hline \multirow[b]{2}{*}{ Health care centre } & \multicolumn{5}{|c|}{ Recurrent cost } & \multicolumn{4}{|c|}{ Capital cost } \\
\hline & Personnel & Administration & Pharmacy & Laboratory & Medical supplies & Building & Vehicle & Equipment & Total \\
\hline Paga & 31125.4 & 10197.6 & 70116.2 & 2133.3 & 2310.9 & 302.9 & 4332.2 & 5505.9 & 126024 \\
\hline Chiana & 75818.2 & 15083.1 & 80853.3 & 1010 & 8512.2 & 143.6 & 7012.3 & 7771.1 & 196204 \\
\hline KNE & 37370.7 & 6732.7 & 8713.4 & 379.3 & 1505.9 & 410 & 3791.1 & 3125.2 & 62028.3 \\
\hline Sirigu & 42368 & 5436.4 & 28728.1 & 3007.3 & 3902.9 & 108.6 & 4668.3 & 5616.9 & 93836.4 \\
\hline $\mathrm{NHC}$ & 60672 & 4726.7 & 66708.1 & - & 875.7 & 252.9 & - & 7247.9 & 140483 \\
\hline Kolgo & 25422.7 & 8525.2 & 88929.3 & 4668 & 2453.8 & 245.7 & 4519.8 & 3567.6 & 138332 \\
\hline Chuchulga & 51720 & 10398.2 & 13310.1 & - & 1479.1 & 102.1 & 1079.8 & 2005.5 & 80094.8 \\
\hline Kanjaga & 56468 & 5963.9 & 3524.3 & - & 1072.8 & 112.1 & 1329.9 & 3501.5 & 71972.4 \\
\hline Siniensi & 113768 & 18848.8 & 6800.6 & - & 1289 & 98.6 & 2962.7 & 4773.7 & 148541 \\
\hline Doninga & 17024 & 534.3 & 5320.4 & 116.7 & 426.5 & 117.9 & 461.7 & 3725.8 & 27727.3 \\
\hline Wiaga & 123852 & 24054.3 & 216272 & 2233.4 & 5741 & 215 & 9276.8 & 8341.2 & 389985 \\
\hline Fumbisi & 99048 & 8970.1 & 40028.4 & - & 3151.7 & 102.1 & 930.7 & 4708.2 & 156939 \\
\hline Total & 734657 & 119471 & 629304 & 13548 & 32721.8 & 2211.4 & 40365.1 & 59890.3 & 1632169 \\
\hline Average & 61221.4 & 9955.9 & 52442 & 1129 & 2726.8 & 184.3 & 3363.8 & 4990.9 & 136014 \\
\hline Median & 54094 & 8747.6 & 34378.2 & 248 & 1908.4 & 130.7 & 3376.9 & 4741 & 132178 \\
\hline
\end{tabular}

of $\$ 23,063$ US (median: $\$ 20,997$ US). The costs attributable to delivery services ranged from $\$ 2,451$ US to $\$ 38,002$ US, with an average of $\$ 11,543$ US per health centre (Table 4). Overall, ANC (17\%) and delivery (8\%) comprised less than a quarter of the total cost of operating the health centres. Based on recurrent expenditures, the average cost attributed to ANC and delivery was $\$ 20,498$ US and $\$ 10,349$ US respectively.

\section{Antenatal visits, deliveries and unit costs}

The average number of antenatal care (ANC) visits was 1,664 per health centre. Based on the recommended minimum of four visits for focused ANC, the estimated average number of women seeking regular ANC was 416. The average number of deliveries was 204, indicating that about $49 \%$ of women who attend ANC delivered at a health facility.

The number of ANC visits and deliveries varied substantially among health centres. For example, while only 270 ANC visits were recorded at Doninga Health Centre, there were as many as 4,074 visits at Navrongo Health Centre (Table 4). In addition, while only 70 deliveries were registered in Doninga, there were 368 deliveries at Paga Health Centre (Table 4). Based on average ANC visits $(1,664)$ and deliveries (204) for the study period, health care centres spent an average of $\$ 18.40$ US per ANC visit and $\$ 63.20$ US per delivery, although these costs varied widely across health care centres. An ANC visit at the Paga Health Centre cost only $\$ 0.99$ US while it cost $\$ 49.17$ US at the Wiaga Health Centre (Table 4).

Similarly, while the estimated cost of delivery was $\$ 12.70$ US at the Chuchulga Health Centre, it was \$152
US at the Siniensi Health Centre. This difference could be attributed to the number of deliveries, as the smaller the number of deliveries, the higher per head cost, and vice versa. Considering recurrent expenditure alone, the average cost per ANC visit was $\$ 1.30$ US and the average cost per delivery was $\$ 56.60$ US per health centre.

The results from the sensitivity analysis (Table 5) show that varying the discount rate applied to capital costs from $3 \%$ to $5 \%$ and life expectancy of buildings from 30 years to 20 years has very little impact on costs (1\%). However, increasing the number of ANC visits and deliveries (by 10\%) has much greater impact on cost. For instance, increasing the number of ANC visits by $10 \%$ (from $1,663.5$ to 1,830 ) resulted in a $32 \%$ reduction in cost per ANC visit (from \$18.4 US to $\$ 12.6$ US), and increasing deliveries by $10 \%$ (from 204.25 to 224.68 ) reduced the unit cost per delivery by $18.75 \%$ (from $\$ 63.23$ US to 51.37 US). This shows that increasing utilization at health centres helps reduce unit costs leading to optimal utilization of the resources.

\section{Discussion}

This study analyzed the costs associated with running a health care centre as well as the specific costs associated with ANC and delivery services. Related studies in the past did not include capital costs in their analysis [12,19] and some studies report results for hospitals only [12]. This study therefore provides empirical evidence to health centre managers and policy makers on the full costs of running a primary health centre and how much is spent on ANC and delivery services. This can help to assess how well resources are used in different health 
Table 4 Cost and unit cost for antenatal care (ANC) and delivery (US\$)

\begin{tabular}{|c|c|c|c|c|c|c|}
\hline \multicolumn{4}{|c|}{ Antenatal care (ANC) } & \multicolumn{3}{|c|}{ Delivery } \\
\hline Health centres & $\begin{array}{l}\text { ANC cost } \\
\text { for the year } \\
2010 \text { (US\$) }\end{array}$ & $\begin{array}{l}\text { Number of } \\
\text { ANC visits for } \\
\text { the year (2010) }\end{array}$ & $\begin{array}{l}\text { Unit cost of } \\
\text { ANC (US\$) }\end{array}$ & $\begin{array}{l}\text { Cost of delivery } \\
\text { services for the } \\
\text { year } 2010 \text { (US\$) }\end{array}$ & $\begin{array}{l}\text { Total number } \\
\text { of deliveries } \\
\text { for the year (2010) }\end{array}$ & $\begin{array}{l}\text { Unit cost of } \\
\text { delivery services for } \\
\text { the year } 2010 \text { (US\$) }\end{array}$ \\
\hline Paga & 2706.54 & 2725.00 & 0.99 & 11590.00 & 368.00 & 31.49 \\
\hline Chiana & 22983.52 & 1588.00 & 14.47 & 5364.00 & 286.00 & 18.76 \\
\hline KNE & 4754.89 & 2237.00 & 2.13 & 5374.00 & 232.00 & 23.16 \\
\hline Sirigu & 8974.69 & 1605.00 & 5.59 & 10413.00 & 313.00 & 33.27 \\
\hline $\mathrm{NHC}$ & 25898.67 & 4074.00 & 6.36 & 18578.00 & 172.00 & 108.01 \\
\hline Kolgo & 24534.52 & 743.00 & 33.02 & 7445.00 & 128.00 & 58.17 \\
\hline Chuchulga & 9929.75 & 1646.00 & 6.03 & 2451.00 & 193.00 & 12.70 \\
\hline Kanjaga & 19179.41 & 1008.00 & 19.03 & 15404.00 & 159.00 & 96.88 \\
\hline Siniensi & 22815.24 & 731.00 & 31.21 & 12160.00 & 80.00 & 152.00 \\
\hline Doninga & 7167.94 & 270.00 & 26.55 & 1792.00 & 70.00 & 25.60 \\
\hline Wiaga & 86285.59 & 1755.00 & 49.17 & 38002.00 & 259.00 & 146.73 \\
\hline Fumbisi & 41526.17 & 1580.00 & 26.28 & 9940.00 & 191.00 & 52.04 \\
\hline Total & 276756.93 & 19962.00 & 220.83 & 138513.00 & 2451.00 & 758.81 \\
\hline Average & 23063.08 & 1663.50 & 18.40 & 11542.75 & 204.25 & 63.23 \\
\hline Median & 20997.33 & 1596.50 & 16.75 & 10176.50 & 192.00 & 42.66 \\
\hline
\end{tabular}

centres and whether these services are sufficiently funded.

The study followed the basic principles and steps of costing health care services recommended by WHO [9] and used in similar studies [10-13]. Though various methods are used in costing health care services, the differences reflect different decision situations and the research objective and not due to disagreement on methodology and concepts $[8,15]$.

The study result showed that there is a significant variation in costs across the selected health centres. This results from differences in patient attendance and available resources at the health centres. The average cost of operating a health centre in our study is higher than the national

Table 5 Sensitivity analysis

\begin{tabular}{|c|c|c|c|c|c|c|}
\hline Variables & $\begin{array}{l}\text { Capital cost } \\
\text { (US\$) }\end{array}$ & $\begin{array}{l}\text { Total cost } \\
\text { (US\$) }\end{array}$ & $\begin{array}{l}\text { ANC cost } \\
\text { (US\$) }\end{array}$ & $\begin{array}{l}\text { Delivery cost } \\
\text { (US\$) }\end{array}$ & $\begin{array}{l}\text { Unit cost per } \\
\text { ANC (US\$) }\end{array}$ & $\begin{array}{l}\text { Unit cost per } \\
\text { delivery (US\$) }\end{array}$ \\
\hline \multicolumn{7}{|l|}{ Discount rate } \\
\hline $3 \%$ discount rate & 8538.90 & 136014 & 23063.08 & 11542.75 & 18.40 & 63.23 \\
\hline *5\% discount rate & 9278.87 & 136754 & 23167.88 & 11593.89 & 18.50 & 63.52 \\
\hline Percentage change (\%) & 7.97 & 0.54 & 0.45 & 0.44 & 0.55 & 0.45 \\
\hline \multicolumn{7}{|l|}{ Building } \\
\hline *Using 20 years life span & 8594.44 & $136,069.60$ & 23069.93 & 11546.33 & 18.41 & 63.26 \\
\hline Percentage change (\%) & 0.65 & 0.04 & 0.03 & 0.03 & 0.07 & 0.04 \\
\hline \multicolumn{7}{|l|}{ Antenatal care (ANC) } \\
\hline Using average number of ANC visits $=1663.5$ & & & & & 18.4 & \\
\hline${ }^{*} 10 \%$ increase in number of ANC visits $=1830$ & & & & & 12.60 & \\
\hline Percentage change (\%) & & & & & 31.51 & \\
\hline \multicolumn{7}{|l|}{ Delivery } \\
\hline Using number of deliveries $=204.25$ & & & & & & 63.23 \\
\hline${ }^{*} 10 \%$ increase in delivery $=224.68$ & & & & & & 51.37 \\
\hline Percentage change (\%) & & & & & & 18.75 \\
\hline
\end{tabular}

*Sensitivity analysis variables. 
average spending on health per capita of \$75 US in 2011 [20]. Furthermore, in comparison with cost studies in other settings, the annual cost of health centres included in this study is higher. In neighbouring Burkina Faso for example, the average recurrent cost of running a health centre is $\$ 63,818$ US [10], which is about half of the average recurrent expenditure in this study. However, since the Burkina Faso study was conducted 10 years ago, the cost difference could be due to increment in staff salaries, general price increases resulting from the depreciation of the Ghana cedi relative to the US dollar over the period (62\% depreciation between 2000-2010) [21] and higher gross domestic product (GDP) per capita in Ghana ( $\$ 3,100$ US) than Burkina (\$1,500 US) [22].

In this study, personnel cost emerged as the most significant cost in running a health centre. This is consistent with other provider cost studies, where personnel cost was above $50 \%$ of the total cost $[12,15,23]$.

The costs attributed to ANC and delivery differ remarkably among the health centres, and the results show that the utilization rate for ANC was higher than for delivery at the health centres. Similar findings have been reported in other studies $[24,25]$. The total ANC and delivery costs represent less than a quarter of the total budget of the health centres, which could be attributed to the underutilization of the services, especially for delivery. Unit cost per ANC visit and normal delivery differ as well among the twelve health centres.

The unit cost per ANC visit using recurrent cost is much lower than observed in other cost studies. For example, while the average recurrent cost per ANC visit in our study was $\$ 1.30$ US, the average recurrent expenditure per ANC visit was estimated at $\$ 2.21$ US in Uganda, \$3.23 US in Malawi, and \$2.97 US in Ghana [19]. However, average recurrent expenditure per delivery in this study was estimated at \$57 US-which is high when compared with \$2.71 US in Uganda, \$10.22 US in Malawi and \$7.66 US in Ghana [19]. Unlike in other studies [23], our findings reveal that higher total costs result in high unit costs, which is due to low ANC and delivery utilization. As the number of ANC visits or deliveries increases, the economies of scale dictate that the unit costs will tend to be less.

The National Health Insurance Scheme (NHIS) of Ghana enables its members to access care in any accredited public, private or mission-run health facility without paying out-of-pocket for services within its benefit package. The scheme then reimburses the providers at a predetermined rate per service provided. The NHIS reimburses the health centres at a rate of $\$ 3.50$ US per ANC service rendered to its clients and $\$ 8$ US per normal delivery [26]. Compared to estimates from this study, the average amounts spent by the health centres per patient receiving ANC and delivery services are higher than the NHIS reimbursement rates for these services. Only two health centres (Paga and KNE) have costs per ANC visit that are within the NHIS antenatal/postnatal reimbursement rate. As for the unit cost per normal delivery, none of the 12 health centres' estimated unit cost fell within the NHIS reimbursement rate. This has implications for cost recovery by the health care centres [27].

\section{Limitations of the study}

The sample size of twelve health centres in this study represents the results only from these centres and may not be generalizable to other regions in the country. Likewise, record keeping and health information systems at the health centres were poor and could affect the study findings. In some instances, we had to rely on estimations, which could lead to either over-estimation or underestimation.

Also, because the health centres were heterogeneous and might differ in efficiency, the total average cost used in the analysis might not be a reliable estimate of actual output cost. In addition, the cost data was based on expenditure of the health care centres and might not reflect the actual cost of producing the outputs such as ANC and delivery.

As few studies have published data on the costs of $\mathrm{MNC}$, it is difficult therefore to meaningfully compare pre-existing data to our study results. This difficulty is also due to the period of data collection, differences in costing methods, differences in prices and resources across settings and general differences in the economic environment. Despite these challenges, the methodology used in this study is applicable across various settings, and the results are relatively reliable and may serve as a starting point for future cost studies.

\section{Conclusions}

This study demonstrated that with painstaking effort, health facility costing is possible in rural settings and the methodology used is appropriate and can be adopted in conducting similar study in another area. The high unit costs reflect underutilization of the existing capacities of the health centres and, therefore, the need to encourage patients to use the health centres. High utilization of ANC and delivery services should improve efficient use of scarce resources and cost recovery for health centres. The study provides useful information that could be used for cost effectiveness analyses of maternal and neonatal care interventions, as well as for policy makers to make appropriate decisions regarding the allocation and sustainability of health care resources.

\section{QUALMAT}

The QUALMAT research project funded as part of the 7th Framework Programme of the European Union (grant agreement 22982) is a collaboration between the Centre de Recherche en Santé de Nouna (Burkina Faso), 
Ghent University (Belgium), Heidelberg University (Germany), Karolinska Institute (Sweden), Muhimbili University of Health and Allied Sciences (Tanzania), and Navrongo Health Research Centre (Ghana). The overall objective of this research is to improve the motivation and performance of health workers and ultimately the quality of pre-natal and maternal care services. The intervention packages include the development and implementation of a system of performance based incentives and a computer-assisted clinical decision support system based on WHO guidelines. The interventions are evaluated in a pre-post controlled study design in rural Burkina Faso, Ghana and Tanzania, between 2009 and 2014.

\section{Consent}

Written informed consent was obtained from respondents for the publication of this report and any accompanying images.

\section{Competing interests}

The authors declare not to have any financial and non-financial competing interests.

\section{Authors' contributions}

MAD contributed to the concept and design of the study, the acquisition of data, data analysis, interpretation of the data, and drafting of the manuscript. PA, GS, HS, HD and SL assisted in the design of the study, development of the data collection instrument and contributed to the write up of the manuscript. JW assisted in the design of the study. RS assisted in the concept and design of the study. All authors read and approved the final manuscript.

\section{Acknowledgements}

We would like to thank the Navrongo Health Research Centre for providing the institutional infrastructure and support for the research team to conduct the study. We are also grateful to the management of the health care centres included in this study for their valuable support during the data collection. A special thanks to European Union for the financial support as the main sponsor of the QUALMAT project (grant agreement 22982).

\section{Author details}

${ }^{1}$ Institute of Public Health, University of Heidelberg, Heidelberg, Germany. ${ }^{2}$ Navrongo Health Research Centre, Navrongo, Ghana. ${ }^{3}$ University of Ghana, School of Public Health, Accra, Ghana. "Behavioural Sciences Department, Muhimbili University of Health and Allied Sciences, School of Public Health and Social Sciences, Dar es Salaam, Tanzania. ${ }^{5}$ Centre for Health Policy Studies, School of Public Health, Zhejiang University School of Medicine, Hangzhou, China.

Received: 2 October 2012 Accepted: 23 July 2013

Published: 26 July 2013

\section{References}

1. Lozano R, Wang H, Foreman KJ, Rajaratnam JK, Naghavi M, Marcus JR, Dwyer-Lindgren L, Lofgren KT, Phillips D, Atkinson C, Lopez AD, Murray CJ: Progress towards millennium development goals 4 and 5 on maternal and child mortality: an updated systematic analysis. The Lancet 2011, 378:1139-1165.

2. Builsa-DHMT: 2010 Annual Report. Builsa District, Upper East Region, Ghana: Builsa District Health Management Team; 2011.

3. KNE-DHMT: 2010 Annual Report. Kassena-Nankana East District, Upper East Region,Ghana: Kassena-Nankana East District Health Management Team; 2011.

4. Oduro AR, Wak G, Azongo D, Debpuur C, Wontuo P, Kondayire F, Welaga P, Bawah A, Nazzar A, Williams J, Hodgson A, Binka F: Profile of the Navrongo Health and Demographic Surveillance System. Int J Epidemiol 2012, 41:968-976.
5. Nyonator FK: The Ghana community-based health planning and services initiative for scaling up service delivery innovation. Health Policy Plan 2005, 20:25-34.

6. QUALMAT: Quality of prenatal \& maternal care: bridging the know-do gap. http://www.qualmat.net/

7. $\mathrm{MOH}$ : Monthly salary levels for health workers on pay scale 2 2(HSS 2). Ghana: Ministry Of Health; 2010.

8. Mogyorosy Z, Smith P: The main methodological issues in costing health care services: a literature review, Working paper. UK: Centre for Health Economics, University of York; 2005. Accessed: February 22, 2012. http://www.york.ac.uk/ media/che/documents/papers/researchpapers/rp7_Methodological_issues_ in_costing_health_care_services.pdf

9. Shepard DS, Hodkin D, Anthony YE: Analysis of hospital costs: a manual for managers. Geneva: World Health Organization; 2000.

10. Mugisha F, Kouyate B, Dong H, Sauerborn R: Costing health care interventions at primary health facilities in Nouna, Burkina Faso. Afr J Heal Sci 2002, 9:69-79.

11. Flessa $S$, Moeller M, Ensor T, Hornetz K: Basing care reforms on evidence: the Kenya health sector costing model. BMC Health Serv Res 2011, 11:128.

12. Aboagye $A Q Q$, Degboe ANK, Obuobi AAD: Estimating the cost of healthcare delivery in three hospitals in Southern Ghana. Ghana Med J 2010, 44:83-92.

13. Conteh $L$ : Cost and unit cost calculations using step-down accounting. Health Policy Plan 2004, 19:127-135.

14. Drummond MF, Sculpher MJ, Torrance GW: Methods for the economic evaluation of health care programmes. 3rd edition. Oxford: Oxford University Press; 2005.

15. Fleßa S: Costing of health care services in developing countries: a prerequisite for affordability, sustainability and efficiency. New York, Oxford: Peter Lang; 2009.

16. Freedberg KA, Kumarasamy N, Losina E, Cecelia AJ, Scott CA, Divi N, Flanigan TP, Lu Z, Weinstein MC, Wang B, Ganesh AK, Bender MA, Mayer $\mathrm{KH}$, Walensky RP: Clinical impact and cost-effectiveness of antiretroviral therapy in India: starting criteria and second-line therapy. Aids Lond Engl 2007, 21(Suppl 4):S117-S128.

17. Joubert G, Ehrlich R: Epidemiology: a research manual for South Africa. 2nd edition. Cape Town, South Africa: Oxford University Press Southern Africa; 2007

18. Umar NA, Fordham R, Ibrahim A, Bachmann M: The provider cost of treating tuberculosis in Bauchi state. Nigeria. J Public Heal Afr 2011, 2:e19.

19. Levin A, Dmytraczenko T, McEuen M, Ssengooba F, Mangani R, Van Dyck G: Costs of maternal health care services in three Anglophone African countries. Int J Health Plann Manage 2003, 18:3-22.

20. World Bank: Health expenditure per capita (current US\$). Washington, DC, USA: The World Bank; 2010. Accessed: August 06, 2012: http://data. worldbank.org/indicator/SH.XPD.PCAP

21. World Bank: THE WORLD BANK: Working for a World Free of Poverty. Washington, DC, USA: The World Bank; 2011. Accessed August 22, 2012. http://data.worldbank.org/indicator/PA.NUS.FCRF?page $=2$

22. GDP-per capita (PPP)-country comparison: http://www.indexmundi.com/g/r. aspx?v=67

23. Dawkinun D, Jikwana S, Setagane S, Maclou B, Mabusela D: Estimating the cost of district hospital services.; 2002. South Africa. A Report retrieved September 24, 2011. http://www.doh.gov.za/docs/reports/2002/findcreport01.pdf

24. Ghana Statistical Service (GSS): Ghana Maternal Health Survey. Calverton, Maryland, USA: Ghana Health Service (GHS), and Macro International; 2009.

25. Akazili J, Adjuik M, Chatio S, Kanyomse E, Hodgson A, Aikins M, Gyapong J: What are the technical and allocative efficiencies of public health centres in Ghana? Ghana Med J 2008, 42:149-155.

26. NHIS: National Health Insurance Scheme (NHIS). Tariffs for Public Facilities. Accra, Ghana: National Health Insurance Authority; 2010.

27. Agyepong I, Yankah B: Understanding the NHIS Provider Payment System and Capitation. Accra, Ghana: Ghana Health Service; 2011. Accessed September 24, 2012. http://www.nhis.gov.gh/_Uploads/dbsAttachedFiles/12.pdf

doi:10.1186/1472-6963-13-287

Cite this article as: Dalaba et al:: Cost of maternal health services in selected primary care centres in Ghana: a step down allocation approach. BMC Health Services Research 2013 13:287. 